\title{
High Temperature Hardness of Bulk Single Crystal GaN
}

I. Yonenaga, T. Hoshi and A. Usui ${ }^{1}$

Institute for Materials Research, Tohoku University, Sendai 980-8577, Japan

${ }^{1}$ Opto-electronics and High Frequency Device Research Laboratories,

NEC Corporation, Tsukuba 305-8501, Japan

\section{ABSTRACT}

The hardness of single crystal GaN (gallium nitride) at elevated temperature is measured for the first time and compared with other materials. A Vickers indentation method was used to determine the hardness of crack-free $\mathrm{GaN}$ samples under an applied load of $0.5 \mathrm{~N}$ in the temperature range $20-1200^{\circ} \mathrm{C}$. The hardness is $10.8 \mathrm{GPa}$ at room temperature, which is comparable to that of Si. At elevated temperatures $\mathrm{GaN}$ shows higher hardness than $\mathrm{Si}$ and GaAs. A high mechanical stability for $\mathrm{GaN}$ at high temperature is deduced.

\section{INTRODUCTION}

GaN (gallium nitride) and its alloys are promising as a wide band-gap, high temperature semiconducting material for application as blue- and ultraviolet-lightemitting devices, and high power/high frequency devices [1]. GaN materials are grown on various foreign substrates with large lattice mismatch and significant differences of thermal expansion coefficient. Such heteroepitaxial structures are inevitably accompanied by the introduction of various kinds of extended defects such as dislocations, prismatic stacking faults, etc. [2]. It is well recognized that the reduction in density of threading defects does lead to improvement of optical and electrical properties of $\mathrm{GaN}$ [3]. Thus, efforts are being made in controlling film stress to reduce the occurrence of detrimental defects during GaN hetero-epitaxial growth to obtain high performance devices. Understanding of dislocation behavior in this material is also indispensable.

The obstacle to conducting such an investigation has been the difficulty in growing bulk $\mathrm{GaN}$ crystal of a suitable size for deformation test. A few investigations are available on dislocation motion or hardness of $\mathrm{GaN}$ at room temperature. Drory et al. [4] measured the hardness and fracture toughness of GaN by a conventional hardness test. Nowak et al. [5] recently evaluated the yield strength of $\mathrm{GaN}$ by nanoindentation. Maeda et al. [6] observed the viscous motion of dislocations under electron irradiation using a transmission electron microscope operating at $200 \mathrm{kV}$. Yonenaga [7] presumed empirically that the activation energy for dislocation motion in $\mathrm{GaN}$ is presumed to be $2 \mathrm{eV}$.

This paper reports the hardness of $\mathrm{GaN}$ at elevated temperature in comparison with those of other typical materials such as $\mathrm{Si}, \mathrm{GaAs}$, etc. As far as we know, this is the first information on the mechanical strength of $\mathrm{GaN}$ at elevated temperature and is important as a basis for the control of dislocation generation during crystal growth. 


\section{EXPERIMENT}

GaN single crystals were prepared from a high quality GaN thick film grown on a 2-inch diameter (0001) sapphire substrate by using hydride vapour phase epitaxy (HVPE) together with the selective growth through $\mathrm{SiO}_{2}$ windows by means of the facet initiated epitaxial lateral overgrowth (FIELO) technique. The details on the growth procedure are described elsewhere [8]. Finally, the thick grown layer was removed from the substrate. As a result, crack-free $\mathrm{GaN}$ single crystals of $0.5 \mathrm{~mm}$ thickness with mirror-like surfaces were successfully obtained and were sufficiently thick to be regarded as being bulk material. The density of grown-in dislocations was as low as $10^{7} \mathrm{~cm}^{-2}$ [9]. Hardness measurements on the crystals were carried out by the Vickers indentation method using a pyramidal diamond indentor. The applied indentation load $P$ was $0.5-5 \mathrm{~N}$, and the dwell time 30 seconds, for every temperature tested in the range from room temperature to $1200^{\circ} \mathrm{C}$ in a high purity $\mathrm{Ar}$ gas atmosphere. Four indents were formed at every temperature for the $\mathrm{Ga}(0001)$ and $\mathrm{N}$ $(000 \overline{1})$ basal plane surfaces.

\section{RESULTS AND DISCUSSION}

Figure 1(a) and 1(b) show an optical micrograph of the indent, formed for the $\mathrm{N}$ $(000 \overline{1})$ surface of $\mathrm{GaN}$ at room temperature $(\mathrm{RT})$ and at $200^{\circ} \mathrm{C}$, respectively. Indents formed for the basal plane surfaces of the samples showed fracture characteristics for brittle materials with a pattern of radial cracks propagating from the indent corners at temperatures lower than $100^{\circ} \mathrm{C}$, while more characteristic deformation without cracks occurred at elevated temperature as seen in figure 1(b).

Hardness $H_{\mathrm{v}}$ was estimated from the load $P$ and diagonal lengths $2 a$, measured by optical microscopy, of the indent using the following relation:
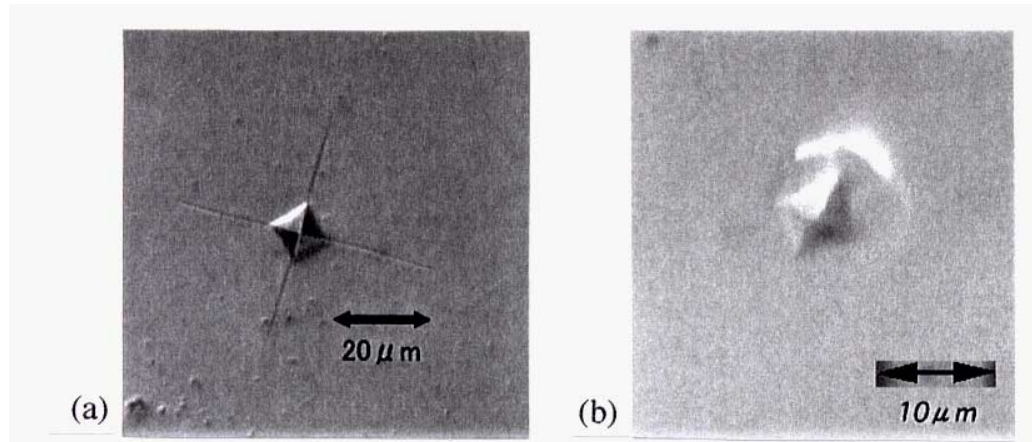

Figure 1. Optical micrograph of Vickers indent of bulk single crystal GaN (a) at RT with an applied load of $1 \mathrm{~N}$ and dwell time of $30 \mathrm{~s}$ and (b) at $200^{\circ} \mathrm{C}$ with $0.5 \mathrm{~N}$ and $30 \mathrm{~s}$. 


$$
H_{\mathrm{v}}=P /\left(2 a^{2}\right) .
$$

The fracture toughness $K_{\mathrm{c}}$ was also determined from the radial crack length $c$ :

$$
K_{\mathrm{c}}=\xi\left(E / H_{\mathrm{v}}\right)^{1 / 2}\left(P / c^{3 / 2}\right),
$$

where $E$ is the Young's modulus and $\xi$ is a calibration constant $(=0.016)$ for brittle materials.

The hardness is comparable for the Ga (0001) and N (000 $\overline{1})$ polar surfaces at all the temperatures investigated and is almost independent of or decreases slightly with an increase in the applied load.

At RT the hardness of GaN is estimated to be $10.8 \mathrm{GPa}$ under the applied load 0.5 - $3 \mathrm{~N}$, about twice the value of GaAs, which is similar to that $12 \mathrm{GPa}$ reported by Drory et al. [4]. In their experiments the applied load was $2 \mathrm{~N}$. Moreover, the fracture toughness is estimated to be $1.1 \mathrm{MPa} \cdot \mathrm{m}$ under the applied load range $0.5-5 \mathrm{~N}$ using Eq. (2) with $E=295 \mathrm{GPa}$ recently reported [5]. Table I summarises the hardness of various semiconductor (111) or (0001) surfaces, together with that of sapphire (0001) surfaces [10], at RT.

Figure 2 shows the hardness $H_{\mathrm{V}}$ of $\mathrm{GaN}$, obtained with an applied load of $0.5 \mathrm{~N}$ and dwell time of $30 \mathrm{~s}$, plotted against reciprocal temperature in comparison with other material (111) or (0001) surfaces. In the whole temperature range investigated, the hardness of $\mathrm{GaN}$ shows a gradual decrease from RT to $500^{\circ} \mathrm{C}$, then something of a plateau in the range $500-1000^{\circ} \mathrm{C}$ and then a steep decrease. Such the temperature dependence is similar to that of $6 \mathrm{H}-\mathrm{SiC}$ and sapphire, with the similar hcp-based structure, although the temperature range and hardness magnitudes of $\mathrm{SiC}$ or sapphire are higher than those of GaN. The plateau may appear in relation to the operation of different slip systems in the crystal structure. It is found that $\mathrm{GaN}$ is harder than $\mathrm{GaAs}$ in the whole temperature range investigated and that at temperatures lower than $600^{\circ} \mathrm{C}$, the hardness of $\mathrm{GaN}$ is comparable to, or a little lower than, that of Si. Surprisingly, up to about $1100^{\circ} \mathrm{C}, \mathrm{GaN}$ maintains its hardness and is harder than $\mathrm{Si}$. Indeed, $\mathrm{Si}$ and GaAs show a steep decrease in hardness from $500^{\circ} \mathrm{C}$ and $200^{\circ} \mathrm{C}$, respectively, with increasing temperature, which means the beginning of macroscopic dislocation motion

Table I. Vickers hardness of GaN and various semiconductors at room temperature or $300^{\circ} \mathrm{C}$ with an applied load of $0.5 \mathrm{~N}$ and dwell time of $30 \mathrm{~s}$. The hardness of sapphire obtained with $2 \mathrm{~N}$ and $15 \mathrm{~s}$ is also included [10].

\begin{tabular}{|ll|l|}
\hline \multicolumn{2}{|l|}{ Material } & \multicolumn{2}{c|}{ Hardness $(\mathrm{GPa})$} \\
\hline $\mathrm{GaN}$ & $(0001)$ & 10.2 \\
$\mathrm{GaAs}$ & $(111)$ & 6.8 \\
$\mathrm{Si}$ & $(111)$ & 12.0 \\
$6 \mathrm{H}-\mathrm{SiC}(0001)$ & $22.9\left(300^{\circ} \mathrm{C}\right)$ \\
$\mathrm{Al}_{2} \mathrm{O}_{3}(0001)$ & $28 \quad($ Ref. 10$)$ \\
\hline
\end{tabular}




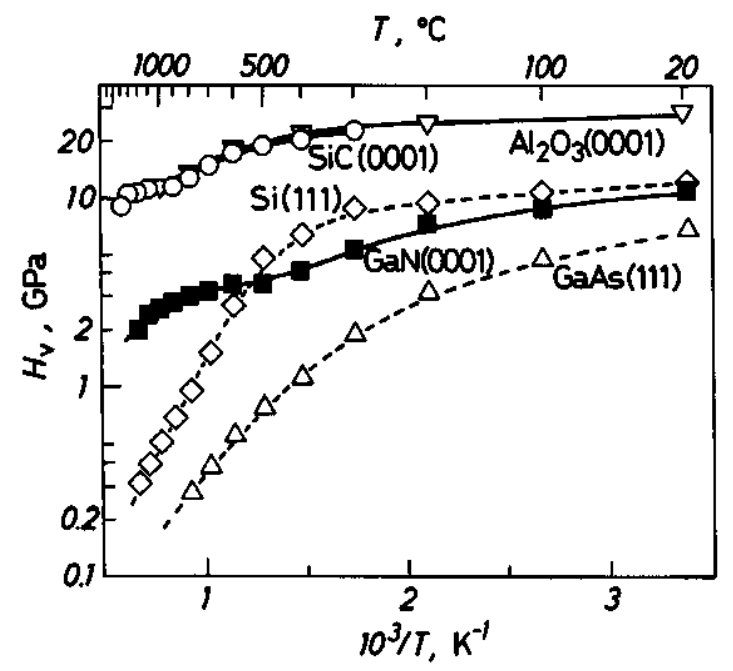

Figure 2. Vickers hardness of bulk single crystal GaN plotted against reciprocal temperature, with an applied load of $0.5 \mathrm{~N}$ and dwell time of $30 \mathrm{~s}$, together with those of $\mathrm{Si}, \mathrm{GaAs}$, and $6 \mathrm{H}-\mathrm{SiC}$. The hardness of sapphire obtained with $2 \mathrm{~N}$ and $15 \mathrm{~s}$ is superimposed [10].

and plastic deformation. Thus, the result for $\mathrm{GaN}$ implies that such macroscopic dislocation motion and plastic deformation may start at around $1100^{\circ} \mathrm{C}$

The present results imply that $\mathrm{GaN}$ has a higher mechanical stability during device processing at high temperatures than $\mathrm{Si}, \mathrm{GaAs}$, and possibly other III-V compounds with the sphalerite structure. Unfortunately, a more complete physical understanding of hardness in order to derive the dynamic properties of dislocations, is still lacking in absence of sufficient theory and is a task in the future. However, we recognise that the present data provide a useful measure of material strength at elevated temperature. Further work is needed to determine dislocation mobilities within $\mathrm{GaN}$ bulk crystals under defined stress distribution.

\section{CONCLUSION}

A Vickers hardness for crack-free bulk single crystal GaN was determined in the temperature range $20-1200^{\circ} \mathrm{C}$. The hardness of $\mathrm{GaN}$ is $\mathrm{c} 10.8 \mathrm{GPa}$ at room temperature and is omparable to that of $\mathrm{Si}$ at temperatures lower than $600^{\circ} \mathrm{C}$. Up to about $1100^{\circ} \mathrm{C}, \mathrm{GaN}$ maintains its harness, being mechanically stable in comparison with $\mathrm{Si}$ and GaAs.

\section{ACKNOWLEDGEMENT}


The authors are grateful to Prof. P. Pirouz of Casewestern Reserve University for the supply of SiC crystals.

\section{REFERENCES}

1. S. Nakamura, M. Senoh, S. Nagahama, N. Iwasa, T. Yamaha, T.

Matsushita, H. Kiyohu, and Y. Sugimoto, Jpn. J. Appl. Phys., 35, L74 (1996).

2. P. D. Brown, in Proceedings of the 8 th International Conference Defect-

Recognition, Imaging and Physics in Semiconductors, Narita, Japan, September, 1999 (to be published).

3. S. Keller, B. P. Keller, Y. -E. Wu, B. Heying, D. Kapolnek, J. S. Speck, U. K. Mishra, and S. P. Den-Baars, Appl. Phys. Lett., 68, 1525 (1996).

4. M. D. Drory, J. W. Ager III, T. Suski, I. Grzegory, and S. Porowski, Appl. Phys. Lett., 69, 4044 (1996).

5. R. Nowak, M. Pessa, M. Suganuma, M. Leszczynski, I. Grzegory, S. Porowski, and F. Yoshida, Appl. Phys. Lett., 75, 2070 (1999).

6. K. Maeda, K. Suzuki, M. Ichihara, S. Nishiguchi, K. Ono, Y. Mera and S. Takeuchi, in Proceedings of the 20th International Conference on Defects in Semiconductors, Berkeley, USA, June, 1999 (to be published).

7. I. Yonenaga, J. Appl. Phys., 84, 4209 (1998).

8. A. Usui, H. Sunakawa, A. Sakai, and A. A. Yamaguchi, Jpn. J. Appl. Phys., 36, L899 (1997)

9. A. Sakai, H. Sunakawa, and A. Usui, Appl. Phys. Lett. 71, 2259 (1997).

10. B. Ya. Farber, S. Y. Yoon, K. P. D. Lagerlöf, and A. H. Heuer, Phys. Stat. Sol. (a) 137, 485 (1993). 